\title{
Study of Austenitic Stainless Steel Castings
}

\author{
Mainak Saha, Department of Metallurgical and Materials Engineering \\ National Institute of Technology (NIT) Durgapur, West Bengal, INDIA
}

\begin{abstract}
Steel casting is a specialized form of casting involving various types of steel. Steel castings are used when cast irons cannot deliver enough strength or shock resistance.Examples of items that are steel castings include: hydroelectricturbine wheels, forging presses, gears, railroad truck frames, valve bodies, pump casings, miningmachinery, marineequipment, turbochargerturbines and engine cylinder blocks.Steel castings are categorized into two general groups: carbon steels and alloy steels. Steel is more difficult to cast than iron. It has a higher melting point and greater shrinkage rate, which requires consideration during mold design. Risers should be given more capacity to draw from as the metal cools and shrinks. Attention should be paid to the thickness of mold cavities, as thinner areas will cool quicker than thicker areas, which can create internal stress points that can lead to fracture.Molten steel is also less fluid than molten iron, making it more difficult to pour and fill intricate gaps in a mold cavity. Molten steel is also more likely to react with internal mold surfaces, making for more unpredictable results. In this paper, the quality of austenitic stainless steel castings will be discussed.
\end{abstract}

Keywords: austenitic stainless steels, liquidus, dendrite, liquidus, multimeter

\section{Material For Investigation}

Twenty-two casts of austenitic stainless steel were produced as $10 \mathrm{~kg}$ air melts with compositions which approximate to AISI 304, 306, 309, 310 and 316. In the 306, 309 and 310 series the main composition variable was $\mathrm{Ni}$ whereas in the 304 and 316 steels $\mathrm{N}$ was varied in the range 0.03 to $0.2 \%$. The steels were chosen as being representative of grades of commercial significance in the region of the phase diagram ofinterest. The exact compositions were chosen to span the solidification boundaries as determined from the Rivlin and Raynor phase diagram. In addition, a further 6 alloys were produced as $5 \mathrm{~kg}$ air melts in order to investigate the effect of $\mathrm{Si}$ on the liquidustemperature.Theliquidus temperature for each melt was determinedusing the Land Checkpoint system.350-400 g of metal was poured into the Checkpoint ceramic crucibles which are equipped with $\mathrm{Pt} / \mathrm{Pt} 13 \% \mathrm{Rh}$ thermocouple heads in silica sheaths. The signal from the thermocouple was displayed on a Thurlby intelligent multimeter. The claimed accuracy of the Land Checkpoint cups is $\pm 0.5^{\circ} \mathrm{C}$ and the sensitivity of the multimeter was $1 \mathrm{pV}$. For each melt 2 liquidus determinations were made to determine the reproducibility of the technique. The maximum difference was $2^{\circ} \mathrm{C}$. The results for the second determination are given in Table 1 together with the chemical analysis of the sample which was determined by a combination of X-ray fluorescence and wet chemistry on drillings.In each case, immediately after the second liquidus measurement the first 22 casts were poured into $100 \mathrm{~mm} \mathrm{X} 50 \mathrm{~mm}$ slab moulds. The ingots were sectioned longitudinally, ground and etched in aqua regia(3HC1:1HN03:4H20). This revealed that all the steels exhibited fully columnar primary and secondary grain structures. An example of the secondary grain structure is shown in Fig. 10. The ingots were sectioned transversely at mid-height and specimens mounted for metallographic examination. Ferrite contents were determined magnetically approximately $10 \mathrm{~mm}$ below the cast surface using a Fischer Ferritescope. The microstructures were revealed by etching in the

following reagent:-

$20 \mathrm{~g}$ Ammonium hydrogen difluoride

$0.5 \mathrm{~g}$ Potassium metabisulphite

$100 \mathrm{ml}$ Water

Etching time: up to $10 \mathrm{~min}$

This etchant stains chromium rich austenite blue and nickel rich austenite yellow whilst ferrite remains white, or black if the ferrite networks are particularly fine. The etch clearly distinguished between the primary dendrites and interdendritic spaces in each steel. However, in the high nitrogen series, Casts 15-22, the colour of the primary phase did not vary systematically with nitrogen content. Some typical structures are shown as black and white micrographs in which the location of the ferrite, either dendritic or interdendritic is clearly visible. In some areas of Cast 19 the 2 typesofferrite appeared to be connected, whereas in other areas they were divorced. The position of the ferrite with respect to the primary dendrites was used to determine the first phase to separate and hence the solidification mode. For example, the presence of ferrite in the primary dendrite is indicative of 
mode B solidification whereas interdendritic ferrite alone is typical of mode $\mathrm{C}$ solidification. Fully austenitic casts are designated mode C/D. These results are presented in A particularly interesting structure was seen in Cast 8 where regions of primary ferritic solidification coexisted with regions of primary austenite. Neither martensite nor o-phase were detectedmetallographically in any of the steels. The stain etch micrographs were used to estimate both the primary and secondary dendrite arm spacings.

These were measured by lineal analysis across 50 intersections. The results are presented in Table 4 where it is immediately obvious that both spacings decreased with increasing alloy content: this was particularly noticeable in the high nitrogen steels, Casts 15-22.

Selected areas of each cast, identified by microhardnessmarks wereanalysed using a CamecaCamebax SX50 microprobe and colour maps of the distribution of $\mathrm{Cr}, \mathrm{Ni}, \mathrm{M \eta}, \mathrm{Si}$ and $\mathrm{P}$ obtained for Casts 1-18 and $\mathrm{Cr}$, $\mathrm{Ni}, \mathrm{M \eta}, \mathrm{Si}$ and Mo for Casts 19-22. The conditions used were as follows:-

Casts 1-14 Casts 15-22

$\mathrm{HV} 15 \mathrm{kV} \quad 15 \mathrm{kV}$

Current $100 \mathrm{~mA} 250 \mathrm{~mA}$

Step length $2 \mathrm{pm} 2 \mathrm{pm}$

Dwell time $50 \mathrm{~ms} 250 \mathrm{~ms}$

Some typical maps for ferritic and austenitically freezing casts are presented in Figs. 17-19. Of particular interest was Cast 1 where some of the interdendritic spaces were enriched in all elements; a typical region is marked A. In addition, linescans were obtained across primary dendrite arms and across interdendritic spaces for each element. Three characteristic probe traces were observed and schematic representations. In general the results for the primary ferritic casts, i.e. those exhibiting dendritic ferrite, agreed with the results from stain etching. In these steels the primary dendrites were enriched in $\mathrm{Cr}$ and depleted in $\mathrm{Ni}$ although in Cast 17 the exact centre of the dendrite was depleted in $\mathrm{Cr}$. The interdendritic regions were enriched in nickel but slightly depleted in $\mathrm{Cr}$. In several casts $\mathrm{Cr}$ was enriched towards the centre of the interdendritic spaces and this resulted in the precipitation of interdendritic ferrite in Casts 19 and 20.

In casts solidifying initially as austenite but containing interdendritic ferrite the centres of the dendrites were depleted in all elements. The interdendritic regions contained ferrite, evident from an increase in $\mathrm{Cr}$ and a depletion in $\mathrm{Ni}$ and $\mathrm{Mn}$ in these areas. Again the results confirm the results of stain etching.

In fully austenitic casts all elements segregated together which implies single phase solidification leading to enrichment in all elements towards the interdendritic spaces. These casts were therefore designated fully austenitic, i.e. mode $\mathrm{D}$, instead of C/D deduced from stain etching.The solidification modes deduced from the EPMA results are compared with those from stain etching in. The cause of the variable response to stain etching observed in Casts 15-22 was not evident from the EPMA results.Liquidus Temperature

As outlined in Section 2 there are several possible methods of calculating the liquidus temperature of austenitic stainless steels, ranging from simple binary depression summations to more complex thermodynamic approaches. Several of these methods have been used in the present investigation and the results are compared with the measured temperatures in Table 6.

The Andrews method of summation of binary depressions gave an average error of $+17.8^{\circ} \mathrm{C}$ which is slightly outside the range for acceptability. This is not surprising since the method was only designed for dilute solutions although Howe3 found reasonable agreement when one element was non-dilute. Very good agreement was found when using the $\mathrm{FeNiCr}$ phase diagram in conjunction with binary depressions for residual elements. The error when using the Chuang and Chang diagram $(\mathrm{C} \& \mathrm{C}$ in Table 6$)$ was slightly lower than obtained from the Rivlin and Raynor diagram (R\&R in Table 6$),-4.9^{\circ} \mathrm{C}$ cf. $-7.4^{\circ} \mathrm{C}$.

However, fewer liquidus temperatures were determined from the Chuang and Chang diagram and there is no real evidence from this work to suggest that either diagram is superior. The use of both diagrams gave acceptable results. Liquidus calculations were then made using MTDATA, a thermodynamic approach developed by NPL and ThermoCalc, a very similar method proposed by the Royal Institute of Technology, Sweden. Several versions of MTDATA are now available to British Steel and these are designated BS1, BS2 and $\mathrm{S} 90$ in

Initially calculations were performed using BS1, the original 12 element version $(\mathrm{Fe}, \mathrm{Cr}, \mathrm{Ni}, \mathrm{C}, \mathrm{P}, \mathrm{S}$, $\mathrm{Si}, \mathrm{Mo}, \mathrm{Mn}, \mathrm{Ti}, \mathrm{N}, \mathrm{O}$ ) used by Howe in an earlier ECSC projects. This gave relatively large errors

(Av. $-36.9^{\circ} \mathrm{C}$ for the first 14 steels) and the error was particularly large for the $2 \% \mathrm{Si}$ steels, Casts $1-5$. The error is plotted against $\mathrm{Si}$ content in Fig. 23 where a clear relationship can be seen. The temperatures were therefore recalculated using BSl for all elements except $\mathrm{Si}$ with the effect of $\mathrm{Si}$ being incorporated as a simple binary depression. The liquidus temperatures calculated in this way are presented under BS1* in Table 6 . It can be seen that the error was much reduced with an average of $-7.7^{\circ} \mathrm{C}$ which is comparable with that obtained using the phase diagram. A plot of measured liquidus against the predicted value is shown in Fig. 24. Large errors (up to $99^{\circ} \mathrm{C}$ ) were also found using ThermoCalc17 with once again the largest errors being associated with the high $\mathrm{Si}$ 
steels. The large error associated with ThermoCalc is not surprising since both methods employ the same source thermodynamic data.The thermodynamic data for Si-containing systems was critically reassessed by NPL, and this resulted in an improved version of MTDATA designated BS2 in Table 6. As part of this work Casts 23-28 were made in order to investigate liquidus temperatures in relevant Si-containing ternary and quaternary systems. It can be seen in Table 6 that the average error was reduced to $-22^{\circ} \mathrm{C}$ but was still highest for the $\mathrm{Si}$ containing steels and alloys (Casts 1-5 and 23-28). When these are omitted the error is reduced to $-19^{\circ} \mathrm{C}$, similar to that found with the Andrews method.As part of the project a subcontract was undertaken by NPL in order to improve MTDATA particularly for high nitrogen steel. The average error of the predicted liquidus temperature for all the steels and alloys was $-22.4^{\circ} \mathrm{C}$ but this was only reduced to $-21.5^{\circ} \mathrm{C}$ when the high $\mathrm{Si}$ melts are omitted.It can be seen from the above discussion that reasonable agreement between measured and predicted liquidus temperature can be obtained by using a relatively simple approach which involves a combination of the FeNiCr phase diagram with the subtraction of binary depressions due to residual or dilute elements. The use of MTDATA as it stands at present did not result in acceptable errors due largely to the element Si. Omitting Si from the MTDATA calculations following by subtracting the binary depression did result in acceptable errors of similar magnitude to the phase diagram approach. Although a limited programmeof work carried out at NPL resulted in improved predictions, the error due to $\mathrm{Si}$ was not entirely eliminated. Clearly additional fundamental thermodynamic work, outside the scope of the present project,is required before acceptable predictions can be obtained from MTDATA. Since the majority of stainless steels contain appreciable Si contents in the range 0.5$2 \%$ the use of MTDATA cannot be recommended for the prediction of liquidus temperatures. It is therefore recommended that the phase diagram approach should be used.

\section{Solidification Structure}

Austenitic stainless steels can solidify initially as austenite or ferrite. In order to rationalise the EPMA work in this project the casts analysed were grouped according to the characteristics shown by the linescans obtained in each case. It was assumed that $\mathrm{Cr}$ partitions to the ferrite phase and Ni to the austenite phase, when both phases are present. Three types of elemental distribution were identified on this basis. They are compared with the results obtained from stain etching.

(1) This type of linescan is illustrated schematically in Fig. 20. This behaviour is consistent with mode B solidification, i.e. primary ferrite with interdendritic austenite. In these casts the dendrite centres were depleted in $\mathrm{Ni}$ and enriched in $\mathrm{Cr}$, indicating primary ferrite precipitation. Within the austenite between the primary dendrites the $\mathrm{Ni}$ content rose moving away from the dendrites and the $\mathrm{Cr}$ concentration fell. This indicates that in this part of the structure, austenite began to be precipitated as a separate phase while the ferrite was still precipitating. At this stage ferrite and austenite must be simultaneously in equilibrium with, and therefore in contact with, the liquid. (The diagram usually used to illustrate mode B solidification is misleading in showing primary ferrite dendrites completely covered or enveloped by austenite.)In addition to this general pattern, seen most clearly between the primary dendrite arms, there were also areas in which all elements increased rapidly in concentration. These represent the final stages of solidification, in which the composition balance in the last pools of liquid was such as to precipitate only austenite, and the levels of solute element rose rapidly due to segregation. In several cases, for example

Cast 19, it was evident from the probe maps, that these highly concentrated areas had precipitated ferrite in the final stages of solidification.

(2) This type of linescan is illustrated schematically, and is consistent with mode $\mathrm{C}$ solidification, i.e. primary austenite with interdendritic ferrite. The centres of the dendrites were depleted in all elements. The interdendritic spaces, however, contained ferrite precipitated in the final stages of solidification, marked by elevated levels offerrite formers, especially $\mathrm{Cr}$, and reduced levels of austenite formers.It can be seen that there was an enrichment in the austenite formers around the ferrite, and also in some cases a variation in concentration of austenite and ferrite formers within the ferrite. This implies that the austenite formers were being rejected from the ferrite as it formed. Ifall the austenite had been fully solid at this stage, rejection of austenite formers in this way would have required a considerable amount of solid state diffusion, making the creation of such a large zone of enrichment difficult. The observation of such a zone therefore indicates that the final stage of solidification consisted of austenite and ferrite precipitating simultaneously from the interdendritic liquid, in a similar manner to that described in case above,rather than the final liquid solidifying as ferrite instead of austenite. As in case (1) the representation ofthe ferrite as dendrites is possibly unrealistic but it is essential that at this stage both ferrite and austenite are in equilibrium with the liquid.

(3) This type of linescan is illustrated in Fig. 22 and is consistent with mode D solidification, i.e. fully austenitic. All the elements showed similar distributions, being relatively depleted in the centres of the dendrites and rising smoothly to a peak in the interdendritic spaces. This distribution reflects the effects of segregation taking place during the solidification of a single phased structure. 
The level of segregation will be determined by the mode of solidification and also by the coarseness of the structure. In general steels solidifying initially as austenite will exhibit higher levels of segregation to the interdendritic spaces than steels solidifying initially as ferrite. Thus the highest levels of interdendritic $\mathrm{P}$ segregation were found in Casts 4,10 and 14, see Table 5, all of which solidified austenitically. A similar effect was not found in the high $\mathrm{N}$ series of steels where low levels of $\mathrm{P}$ segregation were observed in Casts 15-18, whatever the primary phase. P was not analysed in Casts 19-22 but again low levels of Si and Mn segregation were found. This could be due to a strong interaction between $\mathrm{N}$ and $\mathrm{Cr}$ or Mo reducing segregation generally. Alternatively it could result from the much finer primary and secondary dendrite arm spacing resulting in faster homogenisation during cooling.

It can be seen in Table 4 that in general dendrite arm spacing decreased with increasing alloy content. Thus Type 310 structures were finer than Type 309 which in turn were finer than Type 306. However, the effect was most marked in the high nitrogen steels where an increase in $\mathrm{N}$ from 0.03 to approximately 0.10 resulted in a reduction in primary and secondary spacing by a factor of about 2 .

By using $\mathrm{Ni}$ and $\mathrm{Cr}$ equivalent compositions (Equations (1) and (2)) it is possible to use the phase diagram to predict the solidification mode. The modes determined in this way using the Rivlin and Raynor phase diagram. It can be seen that good agreement was found between the predicted and actual primary phases in 18 of the 22 casts. If the mixed structure in

Cast 8 is identified as primary austenitic the structures of 19 of the 22 casts were predicted accurately $(86.4 \%)$. The best agreement was found for the lower alloy steels (Casts 15-22) with the largest deviation being found in Cast 11, a Type 310 stainless steel. An improved fit would be obtained by removing the kink in the mode $\mathrm{B} / \mathrm{C}$ boundary such that the boundary is represented by a straight line of slope

$\mathrm{Cr} / \mathrm{Ni}=1.5$ over the full range of compositions investigated. The revised boundary is shown as a dashed line. In this way the only major error was for Cast 11 whose composition is brought closer to the phase boundary. Similarly, the mode C/D boundary would be better represented by a line of slope

$\mathrm{Cr} / \mathrm{Ni}=1$ and the mode $\mathrm{A} / \mathrm{B}$ boundary by a straight line of slope $\mathrm{Cr} / \mathrm{Ni}=2$. Similar boundaries have been recommended by other workers1 $10-12$.

The kink in the liquidus trough is not present in the phase diagram of Chuang and Chang,

However, on comparing (Rivlin and Raynor diagram) and making adjustments for the different scales employed, it is clear that the liquidus trough is closer to the $\mathrm{Cr}$ axis which is the opposite of the required effect.

MTDATA was then used for the prediction of solidification mode. Initially a ternary model was used employing the same $\mathrm{Ni}$ and $\mathrm{Cr}$ equivalent values used above. The predictions of solidification mode using this method are presented in Table 7. A notable success of MTDATA used in this form was the prediction of the mixed mode of solidification observed in Cast 8.

A similar diagram is constructed using MTDATA.

It can be seen that the phase boundaries are straight lines defined by the following equations:-

ModeA/B, $\mathrm{Ni}=1.68+0.443 \mathrm{X} \% \mathrm{Cr}$

Mode $\mathrm{B} / \mathrm{C}, \mathrm{Ni}=-1.0+0.75 \mathrm{X} \% \mathrm{Cr}$

Mode $\mathrm{C} / \mathrm{D}, \mathrm{Ni}=-2.82+1.0 \mathrm{X} \% \mathrm{Cr}$

The similarity between the slopes of these lines and those recommended for use on the phase diagram is evident. When MTDATA is used in this ternary form good agreement was found between predicted and actual primary phase in 20 of the 22 steels investigated $(90.9 \%)$. Cast 18 was very close to the mode B/C boundary and therefore the one major error was for Cast 21 in which primary ferrite was predicted for a steel undergoing primary austenitic solidification. On several occasions austenite precipitation closely followed the initial separation of ferrite, generally within $2^{\circ} \mathrm{C}$. These steels are all classified as mixed mode $\mathrm{B} / \mathrm{C}$. If we assume that mode $\mathrm{B} / \mathrm{C}$ can indicate either primary austenite or primary ferritic solidification then the number of correct predictions of primary phase were as follows:-

BS1 - 11 out of $14(78.6 \%)$. The errors were all too austenitic.

BS2 - 16 out of $22(72.7 \%)$. The errors were all too ferritic.

S90 - 21 out of $22(95.5 \%)$. The one error in Cast 18 was too ferritic. Examination of the result revealed that austenite precipitation was predicted $7.5^{\circ} \mathrm{C}$ below that for the primary ferrite and therefore the steel was close to the mode $\mathrm{B} / \mathrm{C}$ boundary.

It can therefore be seen that MTDATA in its final revised edition S90 gave improved predictions to those obtained using the original phase diagram of Rivlin and Raynor. There were no major errors with the only minor error being close to being classified as mixed solidification. However, it must be remembered that the phase diagram would be improved by extending the mode $\mathrm{B} / \mathrm{C}$ boundary represented by $\mathrm{Cr} / \mathrm{Ni}=1.5$ over the full range of compositions investigated. This would result in a straight line boundary between primary ferrite and primary austenite as observed with MTDATA in its ternary form. 
The use of MTDATA did not result in any of the steels being classified as fully austenitic or mode D. In fact 6 of the steels were ferrite free and all of these were classed as mode D after EPMA found no evidence of segregation indicative of the presence offerrite on solidification. The 2 phase diagram methods resulted in successful prediction of fully austenitic structures in 2 of the steels, Casts 5 and 10. The unmodified diagram also resulted in Casts 12-14 being predicted to be fully austenitic whereas they actually contained interdendritic ferrite. Modification to the mode C/D boundary resulted in correct predictions of mode $\mathrm{C}$ solidification. However, it should be recognised that transformation and homogenisation will occur below the solidus and therefore the metallographic observations at room temperature are not in serious conflict with the predictions of MTDATA. This is particularly true in the high nitrogen, fully austenitic steels,

Casts 18 and 22, where the very fine structure may have resulted in faster homogenisation.

\section{Residual ferrite}

The ferrite contents of each steel are presented in Table 2 where they are compared with the predicted values using a DeLong diagram2 and the modified Espy equations15. Using the DeLong diagram for the low $\mathrm{N}$ steels, i.e. Casts 1-14, 15 and 19, the actual ferrite content was always lower than the predicted value, i.e. the steels were more austenitic. The maximum discrepancy was $+6.7 \%$ in Cast 2 . For the higher $\mathrm{N}$ steels, i.e. Casts 16-18 and 20-22, closer agreement was obtained with a maximum discrepancy of $+1.2 \%$ for Cast 20 . The relationship between actual and predicted ferrite is shown in Fig. 27. Linear regression gave the following relationship:-

Actual ferrite $=0.61$ (Predicted ferrite) -0.41

The variance explained was $74 \%$.

A better relationship between actual and predicted ferrite content was obtained using the Espy formulae with a maximum discrepancy of $+5 \%$, again for Cast 2. The relationship is shown in Fig. 28. Linear regression gave the following equation:-

Actual ferrite $=0.76$ (Predicted ferrite) -0.04

The variance explained was $78 \%$.

A linear regression of composition against actual ferrite content was performed and this gave the following equation:-

$\%$ Ferrite $=1.45 \mathrm{Cr}+1.6 \mathrm{Mo}-1.4 \mathrm{Ni}-41.9 \mathrm{~N}-5.7$

The variance explained was $82 \%$. The relationship between actual and predicted ferrite using the equation where the close agreement can be seen. However, the equation does not contain a factor for $\mathrm{Si}$ which is a known ferrite stabiliser. Its use outside the range of compositions studied cannot be recommended.

It can be seen from the results that a good agreement between actual and predicted ferrite contents can be obtained over a wide range of composition and solidification mode using a traditional approach, particularly that recommended by Espy. The agreement is generally within $\pm 3 \%$ which is acceptable for predicted ferrite contents. It is therefore considered unnecessary to investigate more complicated methods employing, for example, MTDATA, over the range of compositions examined.

Despite the comments made where there is no conflict between solidification mode and residual ferrite content was found in the present investigation. This is largely due to the observation that the mode boundaries can be represented by straight lines over the range of interest and not the curves depicted in. Thus, mode boundaries and iso-ferrite lines on the DeLong or Espy diagram are both straight.

\section{Acknowledgement}

The author would like to express appreciation and gratitude for the department of Metallurgical And Materials engineering, NIT Durgapur, especially to the foundry laboratory, without whose support and guidance, it would not have been possible to create a review.

\section{References}

[1]. H-U. Lindenberg, Stahl und Eisen, 104, (5), 1984, $\rho$ 51, BISI22871.

[2]. C. J. Long and W.T. DeLong, Welding Jnl. Supplement, 1973,52, $\rho 213$ (s).

[3]. A.A. Howe, Ironmaking and Steelmaking 1988,15, No. 3, $\rho 134$.

[4]. K.W. Andrews and W.E. Bardgett, BS Internal Report 3806/X94/2/55, 1955

[5]. K.W. Andrews, Note submitted to the Alloy Phase Diagram Data Committee of the Metals Society, 1981.

[6]. V.G. Rivlin and V.G. Raynor, Int. Met. Rev. 1980,25, $\rho 21$.

[7]. Y-Y. Chuang and Y. Austin Chang, Metall. Trans. 1987,18A, $\rho 733$.

[8]. A.A. Howe, 'Segregation and Phase Distribution During Solidification of Carbon, Alloy and Stainless Steels', ECSC Agreement No. 7210.CF/801, Draft Final Report, December 1989.

[9]. A Guide to Solidification of Steels', Jernkontoret, Stockholm, 1977.

[10]. Õ. Hammar and U. Svensson, 'Solidification and Casting of Metals', Metals Soc. Pubi. 192, $1979, \rho 401$.

[11]. G. El Nayal and J. Beech, Mat. Sci. and Tech., 1986,2, $\rho 603$.

[12]. N. Suutala, Metall. Trans. 1982,13A, $\rho 2121$.

[13]. T.A. Siewert et al, Welding Research Supplement, Dec. 1988, $\rho 289 \mathrm{~s}$. 
[14]. A.L. Schaeffler, Met. Progr. 1949,56, $\rho 680$.

[15]. R.H. Espy, Welding Research Supplement, May 1982, $\rho 149$ s.

[16]. Land International, Sheffield UK.

[17]. W.T. Chao, British Steel Internal Report SL/PH/TN/6/-/90/A

[18]. M. Wolf, "Metallurgical Seminar on Stainless Steel Casting', Concast Service Union, A.G. Zurich, Sept. 1985.

[19]. B. Janzon, JISI, Oct. 1971, $\rho 826$.

[20]. J.H. Decroix, A.M. Neveu and R.J. Castro, 'Deformation Under Hot Working Conditions', ISI Publication P108, $\rho 135$.

[21]. L. Myllykovski and N. Suutala, Metals Technology, Dec. 1983,10, $\rho 453$.

[22]. M. Fuji and H. Takeuchi, ASM Metal Working Forum, 1974. EJF 